\title{
¿Por qué es importante relacionar a la Comunidad Andina con la descentralización territorial?*
}

\author{
Carolina Blanco Alvarado** \\ David Echeverry Botero \\ German Ortega Ruiz
}

Recibido: 15 de abril de 2020 - Aprobado: 15 de mayo de 2020

El presente artículo es producto del proyecto de investigación FoDEIN: "La actividad administrativa, elemento necesario para el cumplimiento de los fines del Estado", gestionado en el marco de la Facultad de Derecho de la Universidad Santo Tomás, Sede Bogotá.

Citar como: Blanco Alvarado, C., Echeverry Botero, D. y Ortega Ruiz, G. (2020). ¿Por qué es importante relacionar a la Comunidad Andina con la descentralización territorial? Revista IUSTA, 53, 207-225. DoI: https://doi.org/10.15332/25005286.6277

** Abogado de la Universidad Externado de Colombia. Ph.D. en Derecho de la Universidad Santo Tomás, Sede Bogotá. Magíster en Derechos Fundamentales de la Universidad Carlos III de Madrid, España. Especialista en Derecho Constitucional del Centro de Estudios Políticos y Constitucionales de Madrid, España. Especialista en Derecho Administrativo de la Universidad del Rosario, Bogotá. Docente e investigadora de la Universidad Santo Tomás, Sede Bogotá. Correo electrónico: ruthblanco@usantotomas.edu.co.orcid: https://orcid.org/0000-0002-1354-4272.

*** Abogado de la Pontificia Universidad Javeriana, magíster en derecho Económico de esta misma Universidad y Master of Commercial Law (LL.M) de la Universidad de Melbourne. Docente de la Maestría en Derecho Económico de la Universidad Javeriana en las materias de Investigación Científica y Seminario de Investigación. Director de proyectos de investigación en la Maestría en Derecho Contractual Público y Privado de la Universidad Santo Tomás. Se desempeña igualmente como docente de las materias de Derecho Comercial General, Sujetos de Derecho Privado y Economía Política en la Facultad de Derecho de la misma universidad. Correo electrónico: davidecheverry@usantotomas.edu.co.oRciD: https://orcid.org/0000-0003-1893-9836.

Abogado de la Universidad Santo Tomás. Estudiante del programa de cursos para el doctorado de la Universidad de Buenos Aires. Magíster en Derecho Público de la Universidad de Konstanz y de la Universidad Santo Tomás. Especialista en Alta Dirección del Estado de la Escuela de Alto Gobierno. Especialista en Derecho Constitucional de la Universidad del Rosario. Especialista en Derecho Administrativo de la Universidad Santo Tomás. Docente de la Universidad Santo Tomás. Correo electrónico: luis.ortega@usantotomas.edu.co. oRcID: http://orcid.org/0000-0003-2957-5839. 


\title{
Resumen
}

A través del presente manuscrito se pretende justificar la relación entre la integración andina y la descentralización territorial, como sistemas de organización administrativa, descartando en el análisis el escenario de orden económico y prefiriendo para el efecto la perspectiva política y jurídica. La metodología de investigación empleada fue la cualitativa, desde el método de investigación analítico. Para el efecto, se describen ambos fenómenos desde la teoría existente al respecto. Al analizar el marco teórico de la temática en particular, se pudo justificar la relación entre los referenciados sistemas de organización administrativa.

Palabras clave: integración andina, CAN, descentralización territorial.

\section{Why is it important to Link The Andean Community WITH TERRITORIAL DECENTRALIZATION?}

\begin{abstract}
The purpose of this text is to justify the relationship between Andean integration and territorial decentralization as systems of administrative organization, while leaving aside the economic scenario in the analysis and focusing on the political and legal perspective. The preferred research methodology is qualitative, and uses the analytical research method. For this purpose, both phenomena are described from the existing theory on the subject. In analyzing the theoretical framework of the particular subject, it was possible to justify the relationship between the aforementioned systems of administrative organization.
\end{abstract}

Keywords: Andean integration, CAN, territorial decentralization.

\section{Por que é importante relacionar a Comunidade Andina COM A DESCENTRALIZAÇÃO TERRITORIAL?}

\section{Resumo}

Neste artigo, pretende-se justificar a relação entre a integração andina e a descentralização territorial, como sistemas de organização administrativa, descartando, na análise, o contexto de ordem econômica e dando preferência ao efeito da perspectiva política e jurídica. A metodologia de pesquisa utilizada foi a qualitativa, 
sob o método de pesquisa analítico. Para isso, são descritos ambos os fenómenos a partir da teoria existente sobre o particular. Ao analisar o referencial teórico dessa temática, foi possível justificar a relação entre os referidos sistemas de organização administrativa.

Palavras-chave: integração andina, cAN, descentralização territorial.

\section{Introducción}

La articulación de los fenómenos de la descentralización territorial e integración andina evidencia beneficios que vale la pena hacer evidentes. En este orden de ideas, la relación entre los fenómenos de la descentralización territorial e integración ayuda a remover algunos de los obstáculos que no les han permitido a dichos fenómenos cumplir las finalidades por las cuales fueron creados. Para el efecto, la integración andina se constituye en herramienta de gobernabilidad a disposición de los países miembros; y atendiendo a su razón de ser, permite regular desde una perspectiva supranacional la prestación de algunos de los servicios públicos asignados a las entidades descentralizadas territorialmente, como medio ambiente, educación, turismo, salud y transporte, lo cual ayuda a los países miembros en lo relacionado con la tarea de cumplir mejor su carácter de reguladores en la citada prestación. Adicionalmente, dicha integración logra acoplar la institucionalidad de las entidades descentralizadas territorialmente frente al fenómeno de la globalización y, a la vez, concentrar la actividad como Estado nacional, de los Estados andinos, lo cual da lugar a que puedan cumplirse las tareas públicas nacionales más eficientemente. Atendiendo a que el proceso de integración andino permite la participación de la ciudadanía a través de la elección directa de parlamentarios andinos y a través de algunos consejos o comités andinos, es procedente afirmar que dicho proceso promueve la democracia no solo desde el plano supranacional, sino también nacional.

\section{La interdependencia entre la CAN y la descentralización territorial}

A partir de la segunda mitad del siglo xx, confluyeron diversos factores que han contribuido a una mayor interdependencia entre las sociedades pertenecientes a los distintos Estados, tales como: 1) la posibilidad y la conveniencia económica 
de articular mercados transfronterizos de producción y consumo; 2) la posibilidad y la conveniencia económica de atraer la inversión de capitales extranjeros; 3) la masificación y reducción de los costos del transporte y las comunicaciones en todos los órdenes; 4) la intensificación de las relaciones personales, sociales y culturales de índole internacional; 5) el reiterado creciente volumen de información; 6) el crecimiento y la movilidad de la población mundial; y 7) el debilitamiento del poder político del Estado nacional; entre otras muchas, que han ayudado a la conformación de una especie de sistema mundial de perfiles todavía indefinidos y ambivalentes, pero que se nos presenta como una realidad dinámica ciertamente irreversible (Pampillo, 2012).

La interdependencia entre Estados obedece también al fenómeno de la globalización; esta se ha entendido fundamentalmente como un exclusivo fenómeno económico, pero hoy se evidencia su accionar en todos y cada uno de los aspectos de la vida cotidiana del hombre (Blanco, 2015a). La globalización ahora es jurídica y política, ya no solo económica; y es bendecida por los Estados, lo que obliga a las naciones en vía de desarrollo a adoptarla como el único modelo con posibilidades para permanecer en el escenario mundial (Cabrera, 2009). Aunque la globalización es entendida en primera instancia como un fenómeno económico, no puede explicarse solo en términos de simple especialización e interconexión mundial de los medios de producción o como un proceso fundamentalmente económico que consiste en la creciente integración de las distintas economías nacionales en una única economía de mercado mundial (Rockwell, 2005); es pertinente no olvidar que la globalización, tal y como lo explica Sergio de Zubiria Samper, es un conjunto vasto de transformaciones económicas, jurídicas, políticas, sociales, etc. (De Zubiria, 1999).

El fenómeno de la globalización ha generado la disminución del Estado, lo cual es consecuencia, en muy buena medida, por la existencia de nuevos poderes forjados al compás del desarrollo del capitalismo que han adquirido, al calor de la globalización, un poder equiparable al del propio Estado y que gobiernan al mundo; entre otras razones, porque su poder no se encuentra limitado por fronteras (Núñez, 2009). La disminución del Estado genera reducción de las funciones estatales (Lara, 1999) y cuestionamientos relacionados con la soberanía estatal y las bases sobre las que el Estado se ha sustentado históricamente e incertidumbre sobre el papel de las instituciones nacionales y su eficacia a la hora de resolver problemas globales (Blanco, 2014). Es por lo anterior que se han desarrollado nuevas 
perspectivas del concepto de soberanía en la que los organismos internacionales empiezan a jugar papel importante, ya que estos empiezan a vincularse en terrenos antes reservados exclusivamente a las políticas nacionales con el fin de sanear el déficit de credibilidad que padecen los gobiernos nacionales y del Estado mismo (Blanco, 2015b).

El Estado, a través de sus mecanismos de representación y legitimación, era el principal actor de la vida política, un actor libre, autónomo y soberano, dotado de condiciones jurídicas y políticas para la producción de normas y la implementación de políticas. Ese escenario, en la actualidad, es una reminiscencia del pasado. El impacto que la globalización tiene sobre la propia estructura estatal afecta, como es evidente, a su organización institucional y provoca una crisis del principio de soberanía que, de una u otra manera, se traduce a nivel interno también en forma de crisis de legitimidad (Blanco, 2013a).

El Estado, hoy como ayer, es hábil y sabe adaptarse. Con cierta naturalidad ha ido asumiendo el desempeño de los nuevos papeles y nuevas estrategias (Núñez, 2009). Para el efecto, es pertinente anotar que "la globalización está determinando no la obsolescencia del Estado, sino la necesidad de transformarlo en una entidad capaz de conducir una inserción más discriminada y selectiva en la comunidad internacional" (Moncayo, 1999, pp. 15 y 16); lo anterior, en nuestro criterio, supone el fortalecimiento de los procesos de integración, los cuales no se configuran como consecuencias mecánicas de la globalización; ya que la globalización no es integración; es lo opuesto (Blanco, 2013b). La globalización homogeniza, no integra; más bien consolida la desigualdad. "La Integración es un esfuerzo sistemático de los países por juntar sus potencialidades y enfrentar unificadamente sus peligros en el marco de un proceso en el que aceptan formar parte de una unidad supranacional que tiene ventajas y compromisos" (Ayala, 2007, p. 58).

Coincidimos con el criterio del profesor Carrillo, para quien a la fecha existen "profundas transformaciones producidas en el mundo por la aparición de complejos y serios problemas globales" (Carrillo, 1985, p. 13); es por lo anterior que los países han acordado interrelacionarse mediante alianzas tipificadas como integraciones para afrontar tan difícil panorama (Dreyzin, 2007). La realidad mundial presenta la aparición de nuevos escenarios y espacios de relaciones que ya no pueden ser solucionados por las funciones clásicas del Estado-nación (Perotti, 2010); lo que ha llevado a que el concepto de Estado se haya convertido en algo demasiado complejo (Castells, 1998). Es en el referenciado contexto en el que parte de la 
Doctrina ha considerado procedente la reestructuración de la noción de Estado (Estrada, 2006) o de las funciones del mismo, labor en la que, en modo alguno, los procesos de integración deben adquirir importancia. Dentro de los citados procesos de integración se encuentra la Comunidad Andina (en adelante, can), la cual ha de entenderse como una comunidad de derecho que exige por parte de todos los Estados miembros el sometimiento a un mismo derecho en aquellas materias en las que se ha realizado la transferencia del ejercicio de competencias en favor de la Comunidad (Alcoceba, 2008) y como una organización internacional cuya naturaleza jurídica es secundaria y funcional, por cuanto su subjetividad jurídico-internacional depende de la voluntad de los Estados y porque "sus funciones o competencias se restringen a las que explícita o implícitamente les atribuyan los Estados miembros en el derecho primario u originario" (Valencia, 2003, pp. 492 y 493).

Algunos teóricos no aceptan la posibilidad de la integración entre países subdesarrollados aferrándose a la definición básica de la integración que especifica que ella ocurre entre países con un avanzado desarrollo económico (Blanco, 2013c). Para dichos teóricos, la integración surge entre países avanzados industrialmente $\mathrm{y}$, por lo tanto, no puede ocurrir en países del tercer mundo, manifestando que "los llamados casos de integración entre esos países son realmente solo formas de cooperación regional. Es decir, tipos de cooperación y de coordinación política y económica que pueden tener muchos elementos progresistas" (Frambes, 1993). La citada perspectiva es errónea en razón a que la Integración puede ser considerada como un proceso o como un estado o situación. Como proceso, la integración implica "una serie de acciones que los Estados participantes acuerdan cumplir para alcanzar el estado de integración" (Balassa, 1964, p. 1). En este sentido, "la integración no es un producto terminado, sino el camino necesario para llegar a ella" (Torres, 2008, p. 29). La integración como estado o situación es el producto final de la integración como proceso. Se evidencia cuando la integración como proceso ha concluido exitosamente, creando entre los Estados participantes una nueva entidad internacional de carácter permanente y estable. $\mathrm{Al}$ respecto, es pertinente anotar que "es dificultoso hablar de la integración como producto totalmente terminado. Su carácter dinámico, en razón a la necesidad de dar respuesta a la cambiante realidad política y económica, obliga a la modificación de objetivos y mecanismos" (Torres, 2008, p. 29). En este orden de ideas y de conformidad con lo dispuesto anteriormente, resulta procedente afirmar que la can es un verdadero proceso de integración, sustentado en la cooperación internacional de los países miembros, 
que pretende consolidarse, en aras de lograr que los Estados participantes de dicho proceso puedan usufructuar sus beneficios jurídicos, sociales, económicos y político (González, 2016).

En concordancia con lo dispuesto en el párrafo anterior, parte de la doctrina considera que en América Latina existe una incapacidad o falta de voluntad para construir proyectos en común y que por ello no se avanza en una verdadera integración regional; sin embargo, la realidad parecería demostrar que a mediados del siglo xx todos los gobiernos de la región han apostado, en mayor o menor medida, por el tema de la integración regional, ejemplo de ello es la creación de Unasur, Mercosur, Grupo ALBA, CAN, entre otros. Probablemente, la explicación de los limitados resultados obtenidos hasta la fecha esté en el hecho de la falta de continuidad de los grandes objetivos a largo plazo que los propios países desean trazar en torno a las posibilidades y perspectivas de la integración regional; es por ello que, más que incapacidad para construir proyectos en común, el gran problema latinoamericano parecería radicar en la dificultad de perseverar en la construcción de los proyectos de largo plazo concebidos (Mendoza, 2010).

Lo dispuesto en las líneas anteriores es congruente con los cambios que a la fecha ha evidenciado del derecho administrativo, como consecuencia de la internacionalización y globalización del derecho.

En Colombia, son pocos y recientes los estudios de investigación sobre el proceso de integración andino, en tiempos donde sus relaciones internacionales oscilan entre una inserción subordinada a los Estados Unidos y su aislamiento frente a los países vecinos, en una solitaria cruzada del restablecimiento del mito de la seguridad nacional, la autoridad y el orden en una sociedad que parece, al mismo tiempo, desintegrarse y fragmentarse cada día más (Zoido, 2012).

La CAN está conformada en la actualidad por Bolivia, Colombia, Ecuador y Perú. Dicha organización internacional fue creada en 1969 por el Acuerdo de Integración Subregional Andino conocido como Acuerdo de Cartagena, con el fin de "implementar un programa de desarrollo económico que buscaba la industrialización gradual de los países miembros mediante la protección de los mercados nacionales agregados y el estímulo a la complementación productiva” (Bustos, 2010, p. 56). En este sentido, es importante anotar que uno de los principales objetivos del proceso andino de integración es promover el desarrollo equilibrado y armónico de los países miembros en condiciones de equidad e igualdad. 
Luego de más de cuarenta años de haber sido creada, la can ha tenido que pasar por algunos cambios estructurales, en aras de fortalecerse a sí misma como organismo de carácter supranacional. Por ello ha comenzado a plantear la integración en términos más amplios que no se reducen a lo económico, sino que pretenden abarcar la consecución de objetivos comunes en torno a lo político y lo jurídico. En 1969 se suscribe el Acuerdo de Cartagena y nace el grupo andino con el propósito de fundamentar una integración cerrada, a través de la implementación de programas sectoriales de industrialización sustentados en el modelo de desarrollo reinante de la época: el de la sustitución de importaciones. El surgimiento de nuevos retos en la dinámica mundial y la necesidad de profundizar en la integración demandó la introducción de distintas reformas al Acuerdo de Cartagena. Como consecuencia de dichas reformas, a finales de los años ochenta los presidentes andinos se comprometieron a revivir el proceso de integración andina, imprimiéndole nuevas metas más allá de lo puramente comercial y económico.

Las condiciones de negociación establecidas por los Estados en un entorno mundial globalizador han evolucionado radicalmente, colocando a los Estados andinos, en particular, en una situación de indefensión frente a las prioridades y medios de acción disponibles para llevar a cabo su propia integración y posicionarse en la escena internacional. Es por lo anterior que se considera que los procesos de integración deben adquirir relevancia y, como consecuencia de ello, la cesión en el ejercicio de competencias propias del Estado se justifica (Campuzano, 2010). Dentro de los citados procesos de integración encontramos a la can, el cual suscita multiplicidad de reflexiones en el derecho y en la política; sin embargo, en aras de delimitar la temática de estudio, nos dedicaremos a analizar la relación de los sistemas de organización de la descentralización territorial y de integración andina. Lo anterior en aras de generar un insumo para alentar un debate en torno a la marcha de la cAN en el marco de la descentralización territorial.

Lo anterior en razón a que la incorporación de Colombia a la cas plantea aspectos de reflexión relacionados con la repercusión del proceso andino de integración en las competencias descentralizadas territorialmente de dicho Estado. Para el efecto, coincidimos con el profesor Perotti, para quien

la Nación mantiene para sí el derecho supremo de decidir todo lo atinente a la titularidad de la soberanía, sin perjuicio de lo cual puede a su vez, si sus intereses y conveniencia lo aconsejan transferir a organismos creados por Tratados de Integración 
la administración práctica de ciertos campos de su actividad, en particular aquellos relativos a sectores económicos, sociales, jurídicos, culturales, etc. (Perotti, 2007, pp. 441-442)

En este sentido, y como quiera que los procesos de integración implican la transferencia del ejercicio autónomo de competencias de los Estados miembros a órganos supranacionales, y atendiendo a que en el Estado colombiano opera un sistema de organización territorial descentralizado, en el que también funciona la autonomía por parte de las entidades que hacen parte de dicho sistema, resulta de interés y pertinente evaluar en qué medida la transferencia de competencias a entidades territoriales descentralizadas afecta positiva o negativamente al proceso de integración andino. Para el efecto, existen competencias concurrentes en los ámbitos propios de la CAN y de la descentralización territorial, las cuales no se han podido contextualizar en el marco de los citados sistemas de organización administrativa.

La tendencia moderna de los Estados es pasar del Estado centralizado al Estado descentralizado. En este sentido, el profesor Oriol Mir Puigpelat ha considerado que:

[...] se constata paralelamente en muchos países europeos una progresiva descentralización territorial del poder político a favor de las regiones y los entes locales. De esta forma el Estado actual no solo está perdiendo peso hacia fuera, hacia el exterior de sus fronteras, sino también hacia adentro, hacia su interior. Esta progresiva descentralización del poder estatal deriva también, en buena medida y aunque pueda parecer sorprendente, de la propia globalización [...] entre globalización y descentralización existe una familiaridad innata. La globalización lleva una nueva valorización de lo local, a una estrecha interrelación entre los ambientes global y local, conocida y teorizada bajo el nombre de Glocalización. (Mir, 2004, p. 76)

De la lectura de lo dispuesto por el profesor Oriol se puede concluir que existe una relación entre el fenómeno de la globalización y la descentralización. Como consecuencia de ello, se considera pertinente y procedente adelantar un estudio que permita investigar la relación entre el proceso de integración andino y de la descentralización territorial colombiana.

En los últimos años, numerosos estudios han puesto de relieve las trasformaciones del Estado-nación, expresadas de distintas formas: desde arriba, a partir del 
proceso de globalización; desde abajo, a partir de la importancia creciente de las ciudades y de las entidades territoriales a partir del proceso de descentralización. Desde la citada perspectiva, la integración andina, más allá del anhelo y la retórica, requiere también de caminos que permitan concretarla.

Es de interés analizar la incidencia del proceso andino de integración en el marco de la descentralización territorial colombiana; y de la descentralización territorial en el citado proceso de integración. Dicha temática podría ubicarse especialmente en el campo teórico, pero, definitivamente su significación se encuentra igualmente en ámbitos que superan dicho campo. Para el efecto, resulta importante describir la dimensión política y jurídica de la descentralización territorial en el marco del proceso andino de integración; interpretando el diseño del aparato estatal colombiano y de la cAN; y atendiendo las relaciones entre diferentes órganos (Gallego, 2014).

Desde la firma del tratado de creación de lo que en un momento se denominó Pacto Andino, y que ahora conocemos como can, no ha terminado de hacerse clara en la mente de la población la idea del proceso de integración, ni de cuáles son, al fin de cuentas, sus beneficios (Forero, 2014).

Es necesario resaltar que en razón a que los fenómenos de la descentralización territorial y la integración andina no funcionan de manera coordinada, no resulta procedente afirmar que la descentralización territorial colombiana sea obstáculo o avance del proceso andino de integración; y que, precisamente por la ausencia de la citada coordinación, resulta necesario iniciar el proceso de complementariedad de dichos sistemas de organización administrativa.

Los cambios actuales de las relaciones internacionales deben llevar a que las entidades territoriales o sus homólogos empiecen a cobrar importancia en la política exterior. Dichas entidades a través de la CAN podrían participar decididamente en las oportunidades que el mundo externo presenta, lo cual supone un desafío para las relaciones internaciones y para la implementación de las políticas públicas de Colombia, en el citado aspecto. Ahora bien, el objetivo de que las entidades territoriales colombianas participen en el marco de la CAN supone caminos de comunicación entre los gobiernos nacionales de los países miembros de la CAN y dicha organización internacional y de las entidades territoriales con los gobiernos nacionales y la cAN, lo cual constituye todo un desafío que no ha logrado consolidarse, a diferencia de otros procesos de integración, como el de Mercosur, 
en donde los ámbitos subnacionales han empezado a incursionar en el escenario mundial, dando lugar a lo que se ha denominado como paradiplomacia, esto es, al

[...] conjunto de actividades desarrolladas por unidades subnacionales que de una manera individual o conjunta, realizan una acción internacional de manera complementaria y compatible con la diplomacia conducida por el gobierno central, pero con un énfasis en lo local-regional e intereses específicos. (Gómez, Luque y Tinni, 2010)

Lo dispuesto en líneas anteriores, supone una reflexión interdisciplinar porque irradia el marco del derecho administrativo, del derecho constitucional y del derecho comunitario, fundamentalmente porque el objeto de la investigación es el análisis de la norma jurídica comunitaria andina y de la norma jurídica interna, en el marco del derecho interno y del derecho andino; $y$, de esta manera, lo que permitirá estudiar los problemas que suscita la aplicación de la norma comunitaria, sus contradicciones, deficiencias y omisiones. Adicionalmente, la referenciada investigación exige analizar la organización territorial colombiana (tema propio del derecho administrativo) en el marco del derecho andino de la integración, análisis que permitirá proponer algunas modificaciones a la gestión de las entidades territoriales colombianas. Lo anterior con la finalidad de lograr un derecho que vaya más allá de las regulaciones normativas de las tradicionales soberanías nacionales (Dromi, 2003) y, de esta manera, lograr hacia el futuro la configuración de un derecho administrativo supranacional, el cual podría evitar la discrecionalidad administrativa, la eficiencia del gasto e inversión públicos, la preservación de los recursos públicos y el control de los ingresos de los Estados miembros de la CAN, entre otros aspectos. Adicionalmente, en razón a que la temática en análisis irradia al derecho constitucional; es de interés analizar el nivel de articulación del derecho constitucional con el derecho andino de la integración, muy seguramente con la conclusión de la ausencia de articulación entre los citados campos del derecho (Llano, 2013).

La temática en análisis también evidencia un enfoque ius politico, ya que se debe analizar la legitimidad de las normas jurídicas proferidas por la can, la razón de su establecimiento y de sus propósitos políticos. En este sentido, el citado análisis político se puede abordar desde tres perspectivas: 1) como escenario, como actividad y como dimensión humana (Jiménez, 2012); esto es, como espacio de 
confrontación ideológico pragmático para asignar deliberadamente los fines y decidir los objetivos de la sociedad (Lechner, 1986); 2), lo que permite dilucidar un escenario de disputa y antagonismo civilizado en el que se plantean diferentes posiciones y alternativas sobre la manera de entender y resolver los conflictos sociales (Valles, 2001); 3) como actividad tendiente a la consecución, ejercicio y control del poder político. La política, en este sentido, hace referencia a una serie de acciones, conductas y funciones que realizan personas y grupos para poder actuar e incidir en ese escenario de confrontación. La citada perspectiva implica el ejercicio del poder político que cada persona posee como parte del pueblo; así sea en pequeña proporción; también comprende el ejercicio del poder del gobernante o la autoridad, a través de decisiones y políticas públicas. Desde la perspectiva de la dimensión humana, que pretende trascender la contingencia individual y temporal de su ser. Aquí se entiende por política aquella dimensión humana que trasciende los límites propios de la existencia individual (González, 2014).

En consecuencia, el análisis de la relación entre la integración andina y la descentralización territorial supone una perspectiva política-jurídica, descartando el enfoque económico, en primer lugar, porque si bien el núcleo esencial del proceso de integración andino es de carácter económico, antes de debatir sobre la integración económica de los países miembros, es necesario analizar si los Estados andinos están preparados política y jurídicamente para asumir los beneficios y riesgos de dicha integración (Palomares y Calonje, 2015) y, en segundo lugar, porque la doctrina ha hecho notar que la necesidad de la integración, si bien ha sido en primera medida de carácter económico, consecuentemente también es jurídica y política. Coincidimos con el profesor Prieto cuando afirma que es

[...] evidente que el proceso de integración andino se ha enfocado casi exclusivamente hasta ahora en el aspecto económico. Por lo tanto se esperaría que en este ámbito los resultados concuerden con las expectativas. Pero el proceso se ha destacado por su retraso respecto de los plazos previstos y su lenta evolución. (Prieto, 2008, p. 5)

Es por ello que resulta de interés analizar si dicho retraso y lenta evolución obedece a perspectivas diferentes a la económica. Es por lo anterior que se propone desde el enfoque político y jurídico dar respuesta a la aludida relación entre la descentralización territorial y la integración andina (Quiroz, 2014). 
Sin lugar a equívocos, las características intrínsecas de la integración andina y de la descentralización en modo alguno son similares (Humbarita, 2015). En este sentido, el efecto combinado de la integración andina y la descentralización tiende a modificar el papel y las funciones de las entidades territoriales, favoreciendo de esta manera la flexibilidad, la autonomía y la cooperación, mucho más fáciles de llevar a cabo a escala local que a escala central; sin desconocer el papel del Estado central en la coordinación de los entes de decisión para la implementación de políticas públicas (Rodríguez y Guerrero, 2009).

En aras de determinar las similitudes de la can y la descentralización territorial, es pertinente anotar, en primer lugar, que en el proceso de integración andino, al igual que en el fenómeno de la descentralización territorial colombiana, se observa una preponderancia de la rama ejecutiva del poder público, a través del Gobierno central como el agente principal y determinante de los citados procesos. En segundo lugar, al analizar el sistema de organización de la can se evidencia una administración centralizada y descentralizada; estas características jurídicas distintivas determinan la existencia de dos mecanismos esenciales y simultáneos para su fortalecimiento: 1) la administración centralizada del proceso de integración andino a través del funcionamiento e interacción de los órganos e instituciones del Sistema Andino de Integración (saI); y, 2) la administración descentralizada del proceso de integración andino a través de los distintos niveles gubernamentales de cada país miembro. Dicha concurrencia de centralización y descentralización también acontece en el sistema de organización de la descentralización territorial. Para el efecto, es pertinente no olvidar que la descentralización en el Estado colombiano ${ }^{1}$ supone que "las funciones políticas quedan centralizadas, mientras que la función administrativa es descentralizada" (Rodríguez, 1998, p. 49). En este orden de ideas, y para efectos de la descentralización territorial, se evidencia la existencia de dos mecanismos esenciales y simultáneos para su fortalecimiento: 1) la administración centralizada, liderada fundamentalmente, por alcaldías y gobernaciones; y, 2) la administración descentralizada gestionada básicamente por entes descentralizados del orden departamental o municipal, esto es, por establecimientos públicos,

1 En el Estado colombiano concurre una centralización política y una descentralización administrativa; aspecto corroborado por el artículo $1^{\circ}$ de la Constitución al prever que Colombia es un Estado social de derecho organizado como república unitaria, y descentralizado (Rodríguez, 1998, p. 49). Dicho en otras palabras, el Estado se reserva el ejercicio de las funciones constitucional, legislativa y jurisdiccional, mientras que la función administrativa la comparte con otros entes del orden nacional, departamental o municipal (Garzón, 2013). 
empresas industriales y comerciales del Estado y sociedades de economía mixta, entre otros (Rodríguez, 2014).

$\mathrm{El}$ proceso andino de integración y la descentralización territorial evidencian características intrínsecas que son de interés mutuo entre los dos sistemas de organización mencionados. En este sentido, la descentralización territorial supone participación ciudadana, aspecto de supremo interés y necesidad para el proceso andino de integración, ya que dicho aspecto permite promover la legitimidad del proceso andino de integración (Cortes, 2013). La autonomía de las entidades territoriales que pregona la descentralización territorial facilita la gestión de las competencias de la cAN conexas con las competencias de las entidades territoriales descentralizadas, circunstancia de interés para el proceso andino de integración. El sistema de planeación propio del Estado colombiano y de las entidades territoriales es de relevancia para la CAN; ya que para la citada organización internacional la planeación es un factor que permite que esta se convierta en una política de Estado (Patarroyo y Benavides, 2014). La naturaleza jurídica de los departamentos se constituye en herramienta principal para el cumplimiento de las funciones asignadas a la CAN, ya que estos están encargados de la planificación y promoción del desarrollo económico y social de su propio territorio; y, como consecuencia de ello, ser los intermediarios entre los municipios y la nación frente al desarrollo adecuado de las competencias asignadas. La descentralización territorial y el proceso andino de integración funcionan en el marco de la garantía de la tridivisión del poder; lo anterior en razón a que una de las exigencias de tipo político que se impone a los Estados que pretenden ingresar a la cAN es la de que estos se constituyan en Estados de derecho en el que los poderes legislativo, ejecutivo y judicial tengan un ámbito perfectamente delimitado (Barragán, 2016).

\section{Conclusiones}

Uno de los elementos por tener en cuenta en la discusión de los procesos de descentralización es que los mismos estén acompañados de procesos de integración; que para efectos de nuestra investigación se traduce en el hecho de considerar que el desarrollo del sistema de organización administrativo descentralizado territorial se gestione de manera paralela al desarrollo del proceso andino de integración.

Si bien el proceso andino de integración es manifestación propia de las competencias que se enmarcan en las relaciones internacionales del Estado colombiano, 
cuya coordinación y dirección no es de las entidades descentralizadas territorialmente sino del Gobierno Nacional; en la medida en que el Estado colombiano, como Estado unitario, cede el ejercicio de competencias internas a la CAN, a las entidades descentralizadas territorialmente no les queda otra opción que la de adoptar las medidas necesarias para garantizar la ejecución del derecho supranacional; lo que implica que los actos comunitarios se convertirían, pues, en disposiciones de aplicación general y obligatoria para dichas entidades.

La relación jurídica de los fenómenos de la integración andina y la descentralización territorial es de interdependencia; la descentralización territorial colombiana supone no solamente el cumplimiento de las normas propias del derecho interno, sino también de aquellas relacionadas con el derecho andino de la integración. En este orden de ideas, el bloque de legalidad o conjunto de normas a las cuales se encuentran sometidas las decisiones y actuaciones de las autoridades internas se amplía en el sentido de incluir reglas y principios provenientes de la normativa comunitaria.

El globo terráqueo presenta la aparición del fenómeno de la globalización, cuyos efectos no pueden ser solucionados por el concepto de Estado clásico. Es en el referenciado contexto en el que parte de la doctrina ha considerado procedente la reestructuración de la noción de Estado o de sus funciones, labor en la que, en modo alguno, los procesos de integración deben adquirir importancia, y dentro de ellos el proceso de integración andino o cAN.

\section{Referencias}

Alcoceba, M. (2008). La reorientación estatalista del proceso de integración europea. Revista de Derecho de la División de Ciencias Jurídicas, 29, 269-288. Recuperado el 6 de diciembre de 2010 de http://vlex.com/vid/51364983.

Ayala, E. (2007). Enseñanza de integración en lospaíses andinos. Quito, Ecuador: Corporación Editora Nacional.

Balassa, J. (1964). Teoría de la integración económica. Ciudad de México, México: Uteha.

Barragán, D. (2016). La construcción de la mentalidad democrática como necesidad en el posconflicto. Revista Via Inveniendi et Iudicandi, 11(1), 37-57.

Blanco, C. (2013a). Aproximación a la noción de soberanía estatal en el marco del proceso andino de integración. Revista Republicana, 15, 34-67. 
Blanco, C. (2013b). Algunas propuestas frente a la crisis de legitimidad de la comunidad andina. Revista Análisis Político, 26(78), 32-54.

Blanco, C. (2013c). La Comunidad Andina en el marco de lo jurídico y político. Revista Prolegómenos. Derechos y Valores, 26(31), 56-67.

Blanco, C. (2014). La crisis de la comunidad andina. Revista de Derecho, 42, 1-32.

Blanco, C. (2015a). La influencia positiva de la cAN en la descentralización territorial colombiana. Revista Opinión Jurídica, 14(27), 56-67.

Blanco, C. (2015b). La conexión entre descentralización territorial colombiana e integración andina. Revista Análisis Politico, 28(84), 78-98.

Bustos, C. (2010). La Comunidad Andina: historia de sueños y desencuentros. Una visión construida desde la prensa de Colombia. Revista Diálogos de la Comunicación, núm. 79, 89-109.

Cabrera, L. (2009). América Latina y la globalización. Revista Opinión jurídica, 16, 54-76.

Campuzano, A. (2010). ¿Está en crisis el imperio de la ley? La transición paradigmática de la teoría jurídica. Recuperado el 3 de diciembre de 2010 de http://vlex.com/vid/217476633

Castells, M. (1998). El poder de la identidad. En Economía, sociedad y cultura, vol. 2. (pp. 204-235). Madrid, España: Alianza.

Carrillo, J. (1985). El derecho internacional en un mundo en cambio. Madrid, España: Tecnos.

Cortes, S. (2013). La globalización económica y los derechos humanos. Revista Via Inveniendi et Iudicandi, 8(2), 24-47.

De Zubiria, S. (1999). Gestión cultural en un mundo en globalización: perspectivas iberoamericanas. Bogotá D. C., Colombia: Universidad de los Andes.

Dreyzin, A. (2007). La integración como Instrumento para la paz y el desarrollo. El modelo Mercosur en integración regional: una condición para la paz y el desarrollo. Bogotá D. C., Colombia: Universidad Externado de Colombia.

Dromi, R. (2003). Sistema de derecho administrativo. Funciones. Recuperado el 21 de septiembre de 2011 de http://vlex.com/vid/37725667.

Estrada, A. (2006). La lenta agonía de la descentralización. Revista Ratio Juris, 32(4), 98-113.

Forero, J. (2014). El valor superior de la justicia en la Unión Europea. Especial referencia al Estado constitucional social y democrático de derecho español. Revista Verba Iuris, 31, 91-114. Recuperado el 5 de junio de 2018 de https://revistas.unilibre.edu.co/index. php/verbaiuris/article/view/59/53 
Frambes, A. (1993). Teorías sobre la integración aplicables a la unificación de los países latinoamericanos. Revista Política y Cultura, 2. Recuperado el 23 de abril de 2012 de http://vlex.com/vid/204664413.

Gallego, J. (2014). Paradoja y complejidad de los derechos humanos en la sociedad moderna. Sentido y comunicación. Revista IUSTA, 40, 143-165.

Garzón, E. (2013). Globalización del derecho, fetichismo legal el velo de los derechos humanos. Revista Verba Iuris, 30, 56-78.

Gómez, S., Luque, G. y Tinni, H. (2010). La participación de la sociedad civil en los Procesos internacionales. Paradiplomacia. Memorias: V Congreso de Relaciones Internacionales, 24, 25, 26 de noviembre de 2010. Universidad Nacional de la Plata, La Plata, Argentina.

González, O. (2014). La Corte Constitucional como agente del campo jurídico colombiano: la omisión legislativa de principios constitucionales. Revista IUSTA, 41(2), 123-137.

González, O. (2016). La omisión legislativa como hecho generador de la responsabilidad patrimonial del Estado. Revista Verba Iuris, 35, 41-63. Recuperado el 8 de marzo de 2018 de https://revistas.unilibre.edu.co/index.php/verbaiuris/article/view/5/2

Humbarita, J. (2015). Derecho constitucional hispanoamericano frente a la realidad institucional, manifiesta divergencia. Revista IUSTA, 43(2), 45-78.

Jiménez, W. (2012). "Sobre el concepto de política: reflexiones a partir de Carl Schmitt y Norbert Lechner”. Temas de filosofía Politica. Bogotá D. C., Colombia: Universidad Libre.

Lara, E., Cañizares, F., Fung, T. y Ramírez, E. (1999). Globalización, estado y derecho. Revista Cubana de Derecho, 13, 3-10. Recuperado el 4 de diciembre de 2010 de http://vlex.com/vid/47201510.

Lechner, N. (1986). La conflictiva y nunca acabada construcción del orden deseado. Madrid, España: Siglo XXI.

Llano, J. (2013). Prácticas jurídicas locales desde los actores del conflicto armado en Colombia. Revista IUSTA, 39(2), 257-287.

Mendoza, G. (2010). ¿América Latina es incapaz de construir proyectos en común? Recuperado el 2 de enero de 2012 de http://www.can.gov.co

Mir, P. (2004). Globalización, Estado y derecho. Las transformaciones recientes del Derecho Administrativo. Madrid, España: Thomson-Civitas.

Moncayo, E. (1999). Las relaciones externas de la Comunidad Andina: entre la globalización y el regionalismo abierto. Lima, Perú: Secretaría General de la can. 
Núñez, M. (2009). "La crisis del Estado". En Estado, derecho y religión en Oriente y Occidente (21-36). Recuperado el 29 de diciembre de 2012 de http://vlex.com/vid/65576105

Palomares, J. y Calonje, N. (2015). Tratados de libre comercio Colombia-Asia: cuestión preliminar y perfiles de negociación. Revista IUSTA, 43(1), 17-41.

Pampillo, J. (2012). Derecho comunitario y ius commune americano: dos asignaturas pendientes para las ciencias jurídicas de nuestro continente. Revista de Derecho, 18(3), 34-67.

Patarroyo, S. y Benavides, P. (2014). Rupturas asignificantes: revisiones críticas en torno al derecho. Revista Via Inveniendi et Iudicandi, 9(1), 7-31.

Perotti, A. (2007). Habilitación constitucional para la integración comunitaria. Buenos Aires, Argentina: Jurua.

Perotti, J. (2010). La acción internacional de las provincias y municipios argentinos. Memorias: V Congreso de Relaciones Internacionales, 24, 25, 26 de noviembre de 2010. Universidad Nacional de la Plata, La Plata, Argentina.

Prieto, G. (2008). Integración y democracia: aspectos socio politicos del regionalismo en Suramérica. Germán Camilo Prieto Corredor. Colección Gerardo Molina, núm. 17. Bogotá D. C., Colombia: Universidad Nacional. Grupo de Investigación sobre Integración y Democracia: "Demosur".

Quiroz, M. (2014). Acercamiento a las “oposiciones paradigmáticas” entre neoconstitucionalismo y positivismo jurídico. Revista IUSTA, 41(2), 77-97.

Rockwell, J. (2005). Negar la globalización económica ya no es factible en el First National Nank de East Lansing. Míchigan, Estados Unidos, el 19 de abril de 2005. Recuperado el 7 febrero de 2009 de http//www.eldiarioexterior.com/noticia.

Rodríguez, A. (2014). Indicadores de constitucionalidad de las políticas públicas: enfoque de gestión de derechos. Revista Via Inveniendi et Iudicandi, 9(2), 78-98

Rodríguez, C. y Guerrero, H. (2009). Gobernanza multinivel en la Unión Europea. Revista Principia Iuris, 11. Recuperado el 5 de abril de 2013 de http://vlex.com/vid/223723353.

Rodríguez, J. (1998). Derecho administrativo. Bogotá D. C., Colombia: Temis.

Torres, J. (2008). El concepto de integración latinoamericana. Buenos Aires, Argentina: Dunken.

Valles, J. M. (2001). Ciencia politica. Una introducción. Barcelona, España: Ariel. 
Valencia, H. (2003). Ciencia política. Bogotá D. C., Colombia: Universidad Pontificia Bolivariana: Diké.

Zoido, F. (2012). Geografía y ordenación del territorio. Revista Scripta Vetera, 77(2), 19-31. 